\title{
Toward a limbic cortical inhibitory network: implications for hypothalamic-pituitary-adrenal responses following chronic stress
}

\section{Jason J. Radley}

Program in Neuroscience, Department of Psychology, University of lowa, lowa City, IA, USA

\section{Edited by:}

Luke R. Johnson, Uniformed

Services University of the Health

Sciences, USA

Reviewed by:

Jennifer McGuire, Uniformed

Services University of the Health

Sciences, USA

Jay F. Muller, University of South

Carolina School of Medicine, USA

Correspondence:

Jason J. Radley, Program in Neuroscience, Department of Psychology, University of lowa, E11 Seashore Hall, lowa City,

IA 52242, USA.

e-mail: jason-radley@uiowa.edu
A network of interconnected cell groups in the limbic forebrain regulates hypothalamic-pituitary-adrenal (HPA) axis activation during emotionally stressful experiences, and disruption of these systems is broadly implicated in the onset of psychiatric illnesses. A significant challenge has been to unravel the circuitry and mechanisms providing for regulation of HPA output, as these limbic forebrain regions do not provide any direct innervation of HPA effector cell groups in the paraventricular hypothalamus (PVH). Recent evidence will be highlighted that endorses a discrete region within the bed nuclei of the stria terminalis serving as a neural hub for integrating and relaying HPA-inhibitory influences to the PVH during emotional stress, whereas the prevailing view has involved a more complex organization of mulitple cell groups arranged in parallel between the forebrain and $\mathrm{PVH}$. A hypothesis will be advanced that accounts for the capacity of this network to constrain the magnitude and/or duration of HPA axis output in response to emotionally stressful experiences, and for how chronic stress-induced synaptic reorganization in key cell groups may lead to an attrition of these influences, resulting in HPA axis hyperactivity.

Keywords: bed nuclei of the stria terminalis, prefrontal cortex, hippocampus, ventral subiculum, HPA axis, paraventricular nucleus of the hypothalamus, plasticity, dendritic spine

\section{INTRODUCTION}

Stress may be broadly defined as the constellation of physiological and behavioral responses to any challenge that overwhelms, or is perceived to overwhelm, selective homeostatic systems of the individual (Selye, 1980; Day, 2005). A hallmark feature of stress entails activation of the hypothalamic-pituitary-adrenal (HPA) axis. This neuroendocrine cascade is initiated when visceromotor neurons in the paraventricular nucleus of the hypothalamus (PVH) stimulate the release of pituitary adrenocorticotropic hormone (ACTH) into the bloodstream, which, in turn, activates glucocorticoid (GC; cortisol in humans, corticosterone in rodents) secretion from the adrenal gland (Antoni, 1986). GCs are the end-products of HPA axis activation, and facilitate catabolic processes throughout the body during stress by increasing energy metabolism and utilization. GCs also have activating effects on cardiovascular output, and inhibit non-essential processes, such as immune and reproductive functions. Finally, HPA axis activation during stress alters cognitive and emotional processes relevant for behavioral adaptation (e.g., Shors et al., 1992; McIntyre et al., 2003).

Despite the critical role that stress plays for adaptive coping and survival of the individual, it is widely implicated in the onset of psychiatric disease, most notably depression and posttraumatic stress disorder (Kessler, 1997; Yehuda, 2002). Initial studies revealed that patients hospitalized for major depressive illness commonly manifested hypercortisolemia and HPA axis insensitivity to GC receptor agonist treatment (i.e., dexamethasone supression test; Carroll et al., 1976). A wealth of research implicates elevated GCs in compromised brain function, disruptions in the neural circuits imparting negative feedback control over the HPA axis, and further endangerment of brain regions targeted by GCs (for reviews, see Sapolsky et al., 1986; Conrad, 2008). Since the neural substrates providing restraining influences over the stress axis are also regions that play important roles in cognition and emotion, elevated GC levels and HPA axis dysregulation may be key steps in producing the disordered thought and affect that characterize stress-related mental illnesses.

Animal models of repeated stress (e.g., chronic variable stress, chronic intermittent stress, chronic social defeat stress) have proven useful for modeling HPA axis hyperactivity and depression-like behaviors, and would appear to provide the appropriate setting for teasing apart the role of the HPA axis in the pathogenesis of depression. However, progress has been hampered by the fact that the neural circuitry and mechanisms accounting for limbic forebrain control over the HPA axis have proven difficult to unravel. While a number of these candidate regions have been implicated in HPA axis inhibition during emotional stress (Herman et al., 2003; Radley and Sawchenko, 2011), none of these cell groups provide any appreciable direct innervation of the PVH. Combined pathway tracing and immediate-early gene mapping studies have helped to identify a number of candidate cell groups that could serve as disynaptic relays to interface between forebrain regulators and the PVH. The picture that emerges is one involving a complex network of higher-order 
structures interconnected in a parallel and multisynaptic manner with the PVH (Cullinan et al., 1993; Roland and Sawchenko, 1993; van de Kar and Blair, 1999; Herman et al., 2003).

Here we highlight recent advances in our research suggesting an entirely different organization for limbic forebrain control over the stress axis: one involving convergence onto a circumscribed cluster of GABAergic neurons within the anterior bed nuclei of the stria terminalis (aBST), that, in turn, directly inhibits the PVH and HPA activation. This model has several implications for neural circuits and mechanisms underlying HPA axis control and GC-dependent negative feedback. An unforeseen but not incidental feature is that this model helps to clarify the sequelae of chronic stress-induced HPA axis hyperactivity, whereby structural reorganization within limbic forebrain cell groups (i.e., synapse loss/gain) throughout the network leads to an attrition of HPA axis control.

\section{EMOTIONAL STRESS CIRCUITRY: A SEARCH FOR THE MISSING LINK}

Over the years, attempts to organize stressors into a taxonomical framework have resulted in two major groupings, physiological (a.k.a., systemic), and emotional (a.k.a., neurogenic, psychogenic) (Fortier, 1951; Allen et al., 1971). More recent immediate-early gene mapping as a generic index of cellular activation in stress-related circuits has helped to provide a considerable degree of face validity for these distinctions (Cullinan et al., 1995; Li and Sawchenko, 1998; Dayas et al., 2001). Physiological stressors are generally considered to involve more targeted challenges that overwhelm selective homeostatic systems, such as hemorrhage, hypoxia, or immunogenic stimuli. Emotional stressors require interpretation by exteroceptive sensory modalities and integration with distinct cognitive (comparison with past experience) and affective information processing systems in the brain (Herman and Cullinan, 1997; Sawchenko et al., 2000; Dayas et al., 2001). Commonly employed animal models of emotional stress are restraint, immobilization, and footshock. Whereas each class of stressor enlists brainstem and hypothalamic effectors for activation of the sympathoadrenal and HPA axis output, emotional stressors manifest widespread activation in the limbic forebrain, and correspond to a broad array of behavioral changes (e.g., vigilance, fear, anxiety) that help to facilitate adaptive coping as required by the specific environmental demand (Cullinan et al., 1995; Campeau et al., 1997; Li and Sawchenko, 1998; Dayas et al., 2001).

Functional and lesion studies implicate a network of limbic forebrain cell groups in the inhibitory control of HPA activation during emotional stress (Cullinan et al., 1995; Herman and Cullinan, 1997; Akana et al., 2001; Jaferi and Bhatnagar, 2006). Noteworthy examples of regions implicated in HPA axis inhibition are the septum (Feldman and Conforti, 1980b), posterior paraventricular nucleus of the thalamus (PVTp; Jaferi and Bhatnagar, 2006), ventral subiculum (vSUB, the region issuing extrinsic projections of hippocampal formation involved in stress regulation; Herman et al., 1995), and mPFC (Diorio et al., 1993). These cell groups are conspicuously lacking in any direct innervation of HPA effector neurons within the PVH, instead issuing projections throughout numerous basal forebrain and hypothalamic structures (Sesack et al., 1989; Cullinan et al., 1993; Herman et al., 2003). Many of these regions (notably, mPFC and hippocampal outputs) give rise to predominantly excitatory projections, utilizing the neurotransmitter glutamate (MaltheSorenssen et al., 1980; Walaas and Fonnum, 1980; Ottersen et al., 1995), implicating a hitherto unknown, GABAergic relay. Previous work has identified candidate GABAergic cell groups (i.e., preoptic area, aBST, posterior BST, dorsomedial hypothalamic nucleus, PVH-surround regions) between vSUB and PVH (Cullinan et al., 1993), laying a foundation for understanding how controls over the axis may be organized. Nonetheless, whether influences from vSUB, and other HPA-inhibitory cell groups, are mediated via several disynaptic relays arranged in parallel to each other, and which relays are capable of integrating inhibitory signals from the limbic forebrain during emotional stress, has remained elusive.

Our starting point into this problem was to first address the nature of mPFC involvement in acute emotional stress-induced HPA activation, and we have shown that distinct subregions of mPFC differentially modulate the stress axis (Radley et al., 2006a). These studies were inspired from the idea that a variety of other functions subserved by mPFC are differentiated in a dorsal-to-ventral manner (Morgan and LeDoux, 1995; Heidbreder and Groenewegen, 2003). Indeed, previous reports in the stress literature tended to treat the mPFC as a homogeneous structure, and discrepancies remained concerning the nature of mPFC's influence (excitatory or inhibitory) on HPA output (Sullivan and Gratton, 1999; Akana et al., 2001; Figueiredo et al., 2003b; Spencer et al., 2005). Through a series of experiments employing discrete excitotoxin lesions in cortical subfields of $\mathrm{MPFC}$, we found that lesions of dorsal mPFC (encompassing prelimbic cortex, PL, and portions of dorsal anterior cingulate cortex, ACd) enhanced, whereas ventral mPFC (infralimbic cortex, IL) lesions inhibited HPA activation in response to acute restraint stress (Radley et al., 2006a). Furthermore, dorsal mPFC lesions resulted in a prolonged elevation of plasma corticosterone after the cessation of restraint, which is consistent with its role as a target site for GC negative feedback under normal conditions (Diorio et al., 1993) (Figure 1).

Follow-up work has shown that a discrete cluster of GABAergic neurons in aBST forms the missing link in a circuit conveying HPA-inhibitory influences of PL during emotional stress (Radley et al., 2009). First, functional neuroanatomical experiments assayed for sources of GABAergic input to PVH whose sensitivity (i.e., as measured with Fos activation) to an acute stress or (restraint) was diminished by dorsal mPFC lesions. Of the stress-sensitive, GABAergic, PVH-projecting regions analyzed, a circumscribed region in the aBST (corresponding to the dorsomedial and fusiform subdivisions of Dong et al., 2001) was exclusive in showing a decrement in Fos activation following PL lesions (Radley et al., 2009). By contrast, IL lesions were noted to attenuate Fos activation in PVH-projecting neurons in the same region, albeit in a subpopulation of non-GABAergic neurons (Figure 2).

In a second series of experiments, functional ablation of GABAergic neurons in aBST recapitulated the effects of PL lesions on acute stress-induced HPA activation (Radley et al., 2006b, 2009). These studies were performed by focally administering 

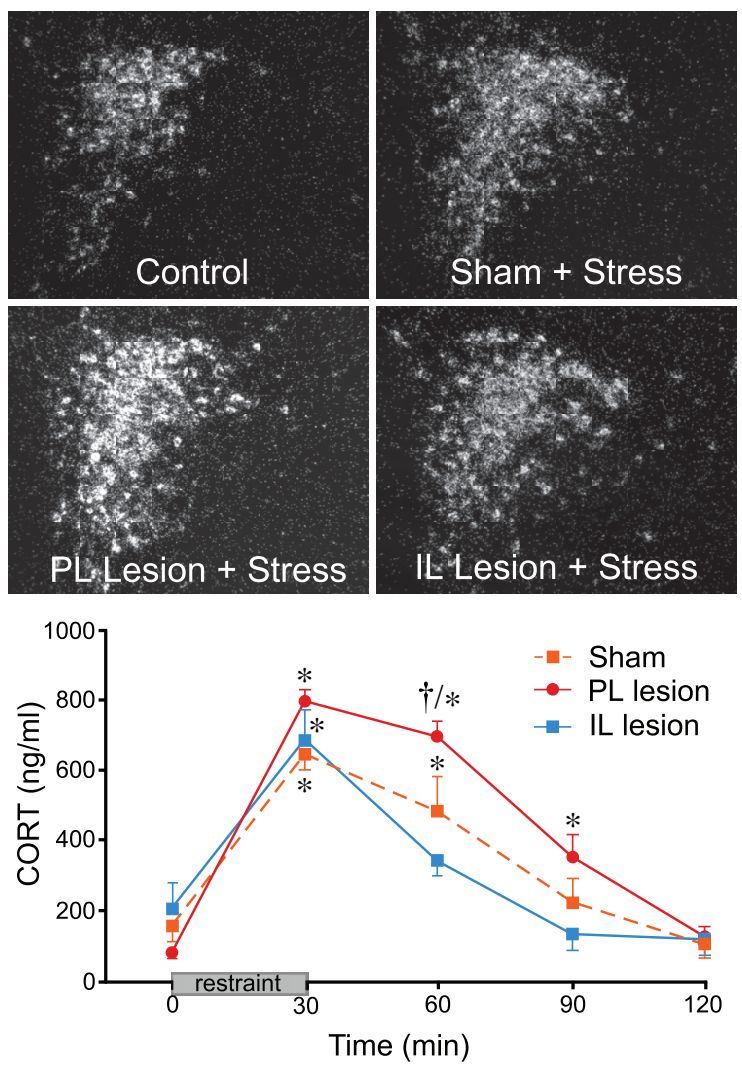

FIGURE 1 | Top: Darkfield photomicrographs showing

corticotropin-releasing factor (CRF) mRNA expression in the paraventricular nucleus of the hypothalamus (PVH) as a function treatment condition. Restraint stress results in a marked increase in CRF mRNA expression in the PVH dorsal medial parvicellular subdivision of intact animals, which is enhanced in prelimbic (PL)-lesioned rats. No such enhancement of stress-induced CRF mRNA expression was seen in infralimbic (IL)-lesioned animals. Bottom: Stress exposure also significantly increases plasma corticosterone (CORT) levels in sham-lesioned animals. PL lesions result in a prolonged increase in stress-induced plasma CORT, while IL-lesioned animals show a more rapid recovery to pre-stress levels. *Differs significantly from basal $(0 \mathrm{~min})$ values from within each group, $p<0.05$; $\dagger$ Differs significantly from sham-lesioned animals for a given time point, $p<0.01$. Data are from Radley et al. (2006a).

an immunotoxin in aBST that preferentially ablates GABAergic, while sparing non-GABAergic, neurons (Radley et al., 2009). Ablation of GABAergic cell groups in aBST enhanced activation of PVH and hormonal indices of HPA axis output in response to acute restraint. Previous reports that indiscriminate lesions to aBST attenuate stress-induced HPA output (Choi et al., 2007), whereas stimulation of aBST may either facilitate or inhibit HPA activity (Dunn, 1987), are consistent with the idea that distinct HPA-regulatory influences arise from neurochemically heterogeneous subpopulations. Thus, opposing influences of the dorsal and ventral mPFC may commingle within the same region of aBST onto separate populations of PVH-projecting GABAergic and non-GABAergic neurons, respectively, to modulate emotional stress-induced HPA output (Figure 3).

Subsequent anatomical pathway tracing studies have that PL is the cortical subfield that provides the source of HPA-inhibitory
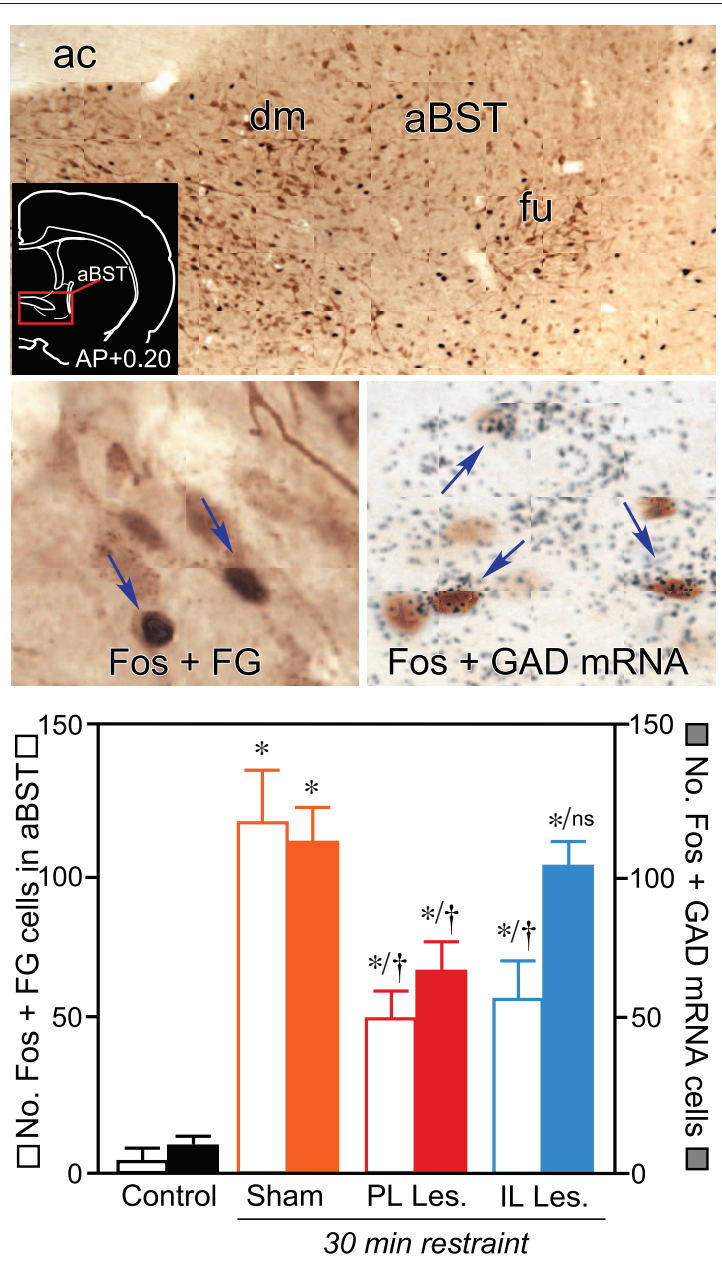

FIGURE 2 | Top: Brightfield photomicrograph showing stress-induced Fos immunoreactivity (black nuclei) and Fluoro-Gold (FG; brown cytoplasm) in anterior bed nuclei of the stria terminalis (aBST). Retrogradely-labeled cells are concentrated in fusiform (fu) and dorsomedial (dm) subnuclei of aBST following tracer injections centered in the PVH. Inset: Coronal section showing the approximate location of aBST corresponding to the region comprising the relevant subdivisions (red box). Middle left: Following restraint stress, cells doubly-labeled for Fos and Fluoro-Gold (arrows) are abundant in sham-lesioned animals. Middle right: Concurrent labeling for Fos (brown) with glutamic acid decarboxylase (GAD67) mRNA (black grains) showing comparable increases in doubly-labeled cells (arrows) in the sham-lesioned group following restraint stress. Bottom: Mean + SEM number of neurons co-labeled for Fos and Fluoro-Gold, and for Fos and GAD67 mRNA, in aBST of treatment groups. Whereas both PL and IL lesions reliably diminished stress-induced activation of PVH-projecting neurons in aBST, only PL lesions resulted in a decrease in the activation of GABAergic neurons in this subregion, implicating different relays for prefrontal modulation of the stress axis. *Differs significantly from sham-lesioned control animals, $p<0.05$. †Differs significantly from sham-lesioned stressed animals, $p<0.05$. Portions of these data have been derived from Radley et al. (2009), and Radley and Sawchenko (2011). Data on IL lesion effects on stress-induced aBST activation are previously unpublished.

influences that emanate from the mPFC (Radley et al., 2006b, 2008b, 2009). Whereas the subcortical projections of dorsal and ventral mPFC are considered to be highly divergent (e.g., Vertes, 2004), their projections to aBST distribute in a topographically 


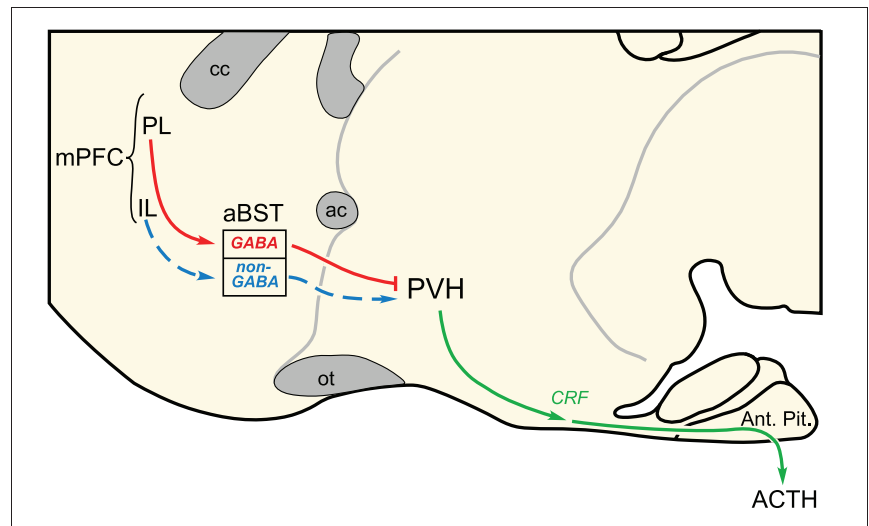

FIGURE 3 | Two disynaptic pathways from medial prefrontal cortex ( $\mathrm{MPFC}$ ) are proposed to account for the differential modulation of emotional stress-induced HPA output. Whereas evidence highlighted in the text [see also, Radley et al. (2009)] supports GABAergic neurons in the anterior bed nuclei of the stria terminalis (aBST) as interceding for the HPA-inhibitory influences of prelimbic cortex (PL; red lines), the pathway from infralimbic cortex (IL) is suggested, and remains to be verified with functional studies. ac, anterior commissure; ACTH, adrenocorticotropic hormone; Ant. Pit., anterior pituitary gland; cc, corpus callosum; CRF, corticotropin-releasing factor; ot, optic tract; $\mathrm{PVH}$, paraventricular nucleus of the hypothalamus.

graded, increasing dorsal-to-ventral manner (Radley et al., 2009). Anterograde tracer injections centered in the most dorsal aspect of mPFC (ACd) fail to label any projections to aBST, more ventrally placed injections label progressively more inputs, with PL providing a moderate innervation of aBST, and IL providing the densest input. Acute restraint stress increases activation of aBSTprojecting neurons throughout PL and IL, and most prominently in the medial-to-rostral aspect of PL (Radley and Sawchenko, unpublished observations). Finally, dual tracing experiments show that PL projections overlap extensively, and make appositions with, PVH-projecting cell groups in aBST (Radley and Sawchenko, 2011).

Insight into the broader organization of HPA axis control has been gleaned from examination of a second limbic forebrain region implicated in the inhibitory regulation of the neuroendocrine stress response. The hippocampal formation (HF) is similar to $\mathrm{mPFC}$ from the standpoint that its extrinsic projections are excitatory, it avoids direct innervation of $\mathrm{PVH}$ proper, and is capable of inhibiting emotional-stress induced HPA output (Swanson and Cowan, 1977; Walaas and Fonnum, 1980; Canteras and Swanson, 1992; Cullinan et al., 1993). Previous studies have shown that HPA-inhibitory influences of HF are localized to vSUB (Herman et al., 1995; Herman and Mueller, 2006), implicating a disynaptic GABAergic relay to PVH. vSUB contains the bulk of the extrinsic projections of HF that innervate candidate PVH-projecting GABAergic cell groups, such as various subregions of the BST and hypothalamus, and preoptic area (Cullinan et al., 1993). Nonetheless, attempts to define the precise relays subserving vSUB influences on the stress axis, or its relation to other relays involved in HPA axis inhibition, had not been previously clarified.

We have found that vSUB influences on the HPA axis are also interceded for by aBST, similar in nature to PL (Radley and
Sawchenko, 2011). First, GABAergic PVH-afferent cell groups in aBST showed a diminished functional activation in animals bearing excitotoxin lesions of vSUB. In these experiments, vSUB lesions were also noted to increase multiple indices of acute restraint-induced HPA activation, as previously reported (Herman et al., 1995). Although HF is not typically regarded as one of the more stress-responsive regions in the limbic forebrain (Li and Sawchenko, 1998), vSUB, particularly its aBST-projecting neurons, does in fact display a moderate degree of engagement following acute restraint stress (Radley and Sawchenko, 2011). Finally, animals bearing dual tracer deposits show that vSUB projections overlap extensively, and make appositions with, stress-sensitive PVH-projecting cell groups in aBST. Collectively, these studies highlight a neural circuitry from vSUB $\rightarrow$ aBST $(\mathrm{GABA}) \rightarrow$ PVH, with each node in the pathway showing functional activation in response to acute restraint stress, and lesions of vSUB resulting in corresponding alterations in output (i.e., decreased aBST, increased PVH/HPA activation).

A key feature of aBST, in addition to its role as a site of convergence, is that it appears to integrate limbic cortical influences (Radley and Sawchenko, 2011). For instance, animals bearing excitotoxin lesions of both PL and vSUB were found to exhibit more exaggerated central indices of stress-induced HPA responses as compared to lesions of either alone. Furthermore, ablation of GABAergic cell groups in aBST produced a greater enhancement of hormonal indices of HPA activation in response to acute restraint, as compared to animals with vSUB lesions alone. Given that dual lesions of PL and vSUB, or separately, by disruption of their interceding inhibitory relay, result in a greater overall effect on stress-induced HPA output than lesions of either, implicates aBST as a key integrator of stress-inhibitory influences emanating from the limbic cortex. Indeed, our examination of the projections of PL and vSUB reveal extensive overlap in their terminal innervation of PVH-projecting neurons within aBST, with evidence of some convergence onto single neurons (Figure 4).

\section{IMPLICATIONS OF AN HPA-INHIBITORY NETWORK}

The elucidation of this network should help to address some of the lingering questions concerning the central organization of HPA control. First is the generality of aBST as a site of convergence and integration of additional forebrain limbic influences on emotional stress-induced HPA output (Figure 5). None of the other forebrain cell groups implicated in the inhibition of emotional stress-induced HPA activity (i.e., septum, posterior paraventricular thalamic nucleus) provides any substantial direct innervation of PVH, although each projects to aBST (Shin et al., 2008). Thus, aBST GABAergic neurons are poised to receive and integrate these along with prefrontal and hippocampal influences. The amygdala is generally considered to exert an excitatory influence on HPA axis activation (Prewitt and Herman, 1997; Sullivan et al., 2004), however, the circuits and mechanisms accounting for this are poorly understood. Both CeA and MeA issue a massive GABAergic input into GABAergic regions of aBST (Sun and Cassell, 1993; Tsubouchi et al., 2007), particularly the aforementioned $\mathrm{PVH}$-projecting population. This suggests that excitatory effects on HPA output may be mediated via disinhibition of this modulatory pathway. The basolateral amygdala (BLA), which 

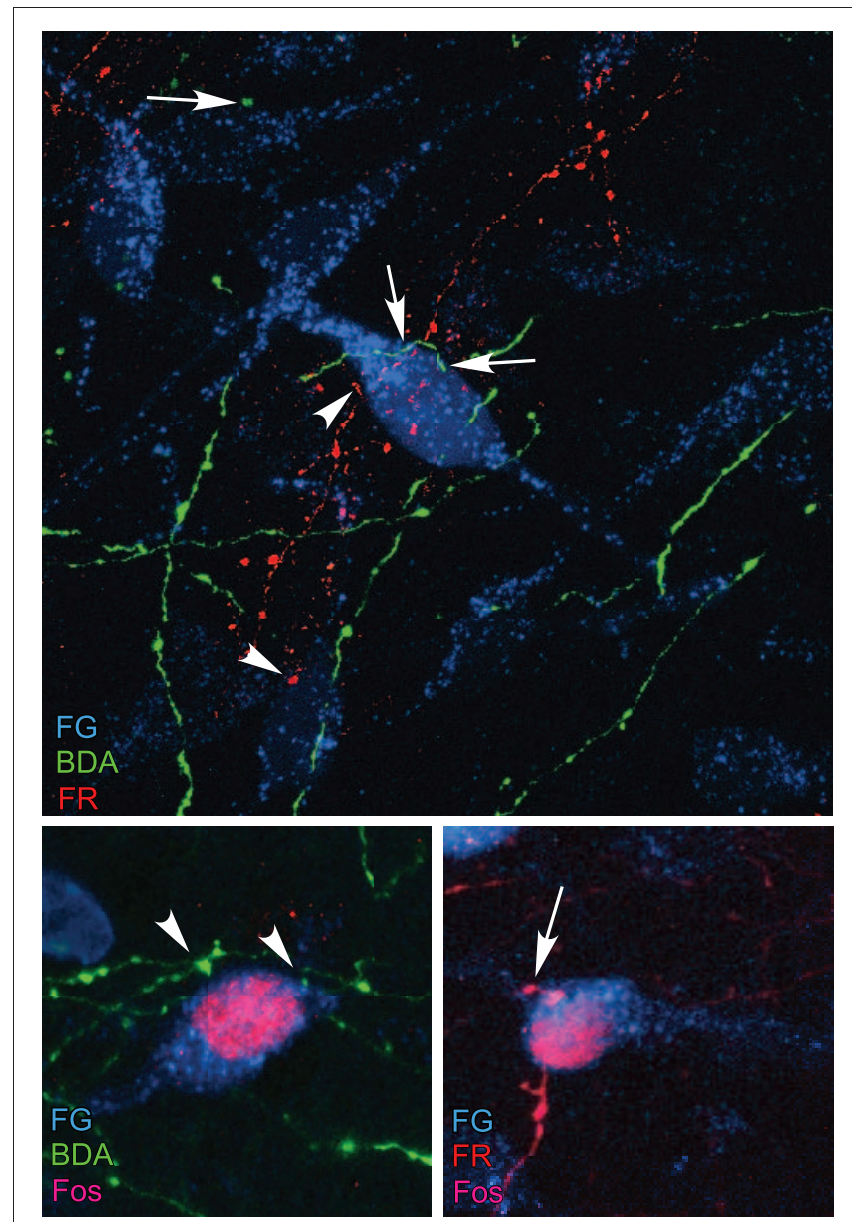

FIGURE 4 | Top: Overlap of retrograde tracer injections in PVH (Fluoro-gold, FG; cyan), and anterograde tracers in PL (BDA; green) and vSUB (FlouroRuby, FR; red) was evaluated in fluorescence preparations using confocal microscopy. Instances of BDA- (arrows) and FR-labeled (arrowhead) terminals were found to make appositions onto single $\mathrm{PVH}$-projecting neurons in aBST, by analysis of single optical planes containing fluorescence labeling for all three markers. Bottom row: After a single stress exposure, numerous instances of Fos-labeled nuclei are evident in PVH-projecting neurons containing appositions from BDA- (left) and FR-labeled (right) terminals. Data are based upon Radley and Sawchenko (2011)

consists predominantly of pyramidal-like glutamatergic neurons, is also implicated in stimulating emotional stress-induced HPA activation (Bhatnagar et al., 2004). One likely scenario is for BLA to access the PVH via the BLA-to-CeA pathway widely implicated as the direction of information flow for the genesis of fear-related autonomic and behavioral responses (Pitkanen et al., 1997; LeDoux, 2000), then proceeding via a CeA (GABA) $\rightarrow$ aBST $(\mathrm{GABA}) \rightarrow$ PVH pathway.

The model as proposed may also help to advance our understanding of the circuits and mechanisms accounting for GC receptor-mediated negative feedback. A number of cell groups implicated in inhibiting emotional stress-induced HPA activation (i.e., PL, HF, PVTp, lateral septum) are also capable of imparting GC receptor-mediated negative feedback on the axis (Feldman and Conforti, 1980a; Jacobson and Sapolsky, 1991; Diorio et al.,

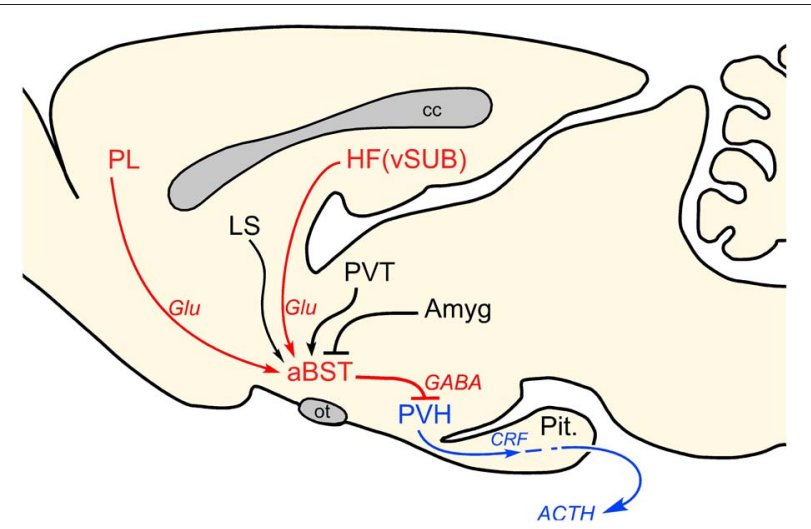

FIGURE 5 | Proposed role of anterior bed nuclei of the stria terminalis (aBST) as an integrator of limbic forebrain influences on emotional stress-induced HPA output. Previous work of ours supports the pathways highlighted in red, with aBST providing an important source of GABAergic innervation of $\mathrm{PVH}$, and relaying limbic cortical influences. Other forebrain cell groups known to influence HPA output (highlighted in black), notably via GC receptor-mediated negative feedback, also project to aBST, whose integrated output targets PVH directly. Like ventral subiculum (vSUB) and prelimbic cortex $(\mathrm{PL})$, these regions do not provide any appreciable innervation of $\mathrm{PVH}$, but do issue projections to the aBST. ACTH,

adrenocorticotropic hormone; Amyg, amygdala; cc, corpus callosum; CRF, corticotropin-releasing factor; Glu, glutamate; HF, hippocampal formation; LS, lateral septum; ot, optic tract; Pit., pituitary gland; $\mathrm{PVH}$, paraventricular nucleus of the hypothalamus; PVT, paraventricular thalamic nucleus.

1993; Jaferi and Bhatnagar, 2006). This raises the possibility that aBST may integrate steroid-dependent feedback information from the limbic forebrain for conveyance to the PVH. Evidence increasingly suggests that GC negative feedback in the limbic forebrain may be mediated via an endocannabinoid signaling mechanism. For example, Hill and colleagues (2011) recently reported that GC receptor activation in $\mathrm{MPFC}$ neurons mobilizes the release of endocannabinoids and increases excitatory outflow from principal neurons via the presynaptic inhibition of GABA release from local interneurons (Hill et al., 2011). Understanding of a broader circuitry for imparting inhibitory influences over the stress axis should allow for assessment of whether GC negative feedback is restricted to upstream mediators, or whether aBST can intercede for these influences as a proximate source of steroidmediated feedback, and, the generality of endocannabinoid signaling in relaying GC-dependent feedback in other components of the network.

Finally, if the proposed framework is inhibitory in nature, this helps to clarify a fundamentally important question of what drives the initial activation of PVH and HPA output during stress. As previously noted, IL appears to exert an excitatory influence on HPA output via a distinct realy in aBST, and may comprise one of the upstream components for an activating network. The idea that a non-GABAergic subpopulation of aBST neurons relays excitatory influences from IL to the PVH is consistent with evidence that indiscriminate excitotoxin lesions in aBST reliably attenuate acute emotional stress-induced HPA output (Choi et al., 2007). One proposal from Choi and colleagues (2007) is that the non-neuroendocrine CRF-expressing subpopulation within aBST (corresponding to the fusiform subdivision of Dong et al., 2001) 
may provide a source of excitatory input into $\mathrm{PVH}$, and future studies will help to clarify this relationship further. At least with regard to physiological stress, HPA output appears to be mediated predominantly via medullary aminergic inputs to $\mathrm{PVH}$, as ablation of this pathway completely blocks central and peripheral indices of HPA activation under exposure to these challenges (Ritter et al., 2003; Schiltz and Sawchenko, 2007). By contrast, this pathway does not mediate HPA activation during acute emotional stress (Ritter et al., 2003; Schiltz and Sawchenko, 2007), and evidence for an equivalent activating system under this category of challenges remains elusive.

\section{CHRONIC STRESS-INDUCED NETWORK REORGANIZATION}

Chronic stress induces profound structural and synaptic changes in a variety of limbic forebrain regions. mPFC (ACd, PL, and IL) and CA3 hippocampal neurons show regressive alterations in apical dendritic and synapse morphology (Watanabe et al., 1992; Magarinos and McEwen, 1995a; Cook and Wellman, 2004; Radley et al., 2004, 2006b; Stewart et al., 2005; Hajszan et al., 2009), whereas amygdala (BLA) neurons show increases in these indices (Vyas et al., 2002, 2006). These changes are paralleled by reductions in gray matter volume and functional impairments in mPFC and HF of depressed individuals (Sheline et al., 1996, 2003; Drevets et al., 1997). Generally speaking, stress-induced structural plasticity is dependent on elevated GCs and excitatory glutamatergic signaling (Liu et al., 2008; Magarinos and McEwen, 1995b). Such structural alterations have been linked with disruptions in learning and memory (Luine et al., 1994; Stewart et al., 2005; Liston et al., 2006; Dias-Ferreira et al., 2009; Holmes and Wellman, 2009; cf. Conrad, 2010), and increases in anxietylike behaviors (e.g., elevated plus maze performance; Mitra et al., 2005). HPA axis hyperactivity (i.e., sensitization, facilitation) is also widely documented to result from chronic stress (Ottenweller et al., 1989; Dallman et al., 1992; Willner, 1997; Bhatnagar and Dallman, 1998; Figueiredo et al., 2003a; Weinberg et al., 2010), although its relation to structural plasticity in the limbic forebrain remains to be thoroughly examined.

Much of the previous literature relevant to studying the effects chronic stress on structural plasticity entailed examination of dendritic branching patterns. This is likely due to the fact that stress and GCs produce robust changes on neurons that are readily manifest at the morphological level, and that changes in dendritic branching patterns (i.e., complexity, length, branch numbers) generally were thought to correlate with changes in synaptic connectivity. Nonetheless, increasing attention has been given to more detailed analyses of synaptic alterations in neural circuits following chronic stress, given their critical role as junctional points of connectivity that mediate information flow between neurons. Dendritic spines represent sites of postsynaptic contact for the majority of excitatory synaptic input in cortical structures. Spines are highly motile and dynamic structures that exhibit a wide degree of morphological diversity, with alterations in shape and number providing a cellular correlate for learning capacity, learning, and memory (Bailey and Kandel, 1993; Sorra and Harris, 2000; Kasai et al., 2003; Wilbrecht et al., 2010). Despite the heterogeneity of spine morphology, their classification into broad categories has proven useful. For instance, long and thin spines tend to be regarded as immature, and are more abundant during development, whereas mushroom-shaped spines (large diameter head, small diameter neck) represent stronger, more well-established excitatory synapses.

A number of studies suggest that chronic stress leads to a net loss of excitatory synapses in PL neurons (Radley et al., 2006b; Michelsen et al., 2007; Liu and Aghajanian, 2008; Arnsten, 2009). Notably, dendritic spines in the distal portions of the apical dendritic tree appear to be most profoundly impacted by chronic stress, inclusive of retraction of distal processes and decreases in spine density (Figure 6) (Radley et al., 2006b; Liu and Aghajanian, 2008). We conducted a high-throughput analysis of over 17,000 dendritic spine morphologies in PL and ACd pyramidal neurons (Radley et al., 2008a), and found that chronic stress resulted in an overall decrease in apical dendritic spine density, manifested by a loss of mushroom-shaped spines, and an increased frequency of long and thin spines. Another recent report employing two-photon microscopic in vivo imaging of spines in has provided the most compelling evidence to date for the capacity of GCs to mediate stress-induced spine alterations in the cortex (i.e., primary motor, secondary motor, somatosensory; Liston and Gan, 2011). Whereas acute GC exposure increased the rate of spine turnover (elimination and formation), prolonged GC exposure selectively increased the elimination of spines, particularly ones that were older and more stable. These, and other studies (Michelsen et al., 2007; Liu and Aghajanian, 2008), support the idea that chronic stress, via increases in GC levels, may selectively target the mature, stable population of excitatory synapses throughout cortical structures.

Chronic stress has also been shown to decrease synapse and spine density in hippocampal neurons (Sousa et al., 2000; Sandi et al., 2003; Stewart et al., 2005; Hajszan et al., 2009). In one of the more rigorous demonstrations of this phenomenon, one study employed electron microscopy (EM) and stereological 3-D reconstructions in, finding that chronic stress induced significant decreases in dendritic spine density and synapse number, and was reversible following a stress-free recovery period (Sandi et al., 2003). In another study employing EM, Magarinos and colleagues (1997) reported ultrastructural differences in presynaptic terminals of synapses in the mossy fiber pathway in CA3 neurons following chronic stress, indicative of an up-regulation of presynaptic activity and release of glutamate. Taken together, decreases in density and in overall numbers of postsynaptic excitatory contacts may help to limit the extent of excitotoxic damage that would otherwise result from prolonged activation of glutamatergic synapses under chronic stress.

A number of studies have begun to identify the cellular mechanisms underlying chronic stress-induced spine synapse loss (for reviews, see Arnsten, 2009; Duman and Voleti, 2012). For example, reduced expression of certain neurotrophic/growth factors (notably, brain-derived neurotrophic factor) in the hippocampus, and more recently in $\mathrm{mPFC}$, may contribute to dendritic spine synaptic compromise in these regions (Liu et al., 2012; Nibuya et al., 1995; Kuipers et al., 2003). Alterations in protein kinase $\mathrm{C}$ signaling have also been shown to underlie dendritic spine loss in mPFC (Hains et al., 2009). Finally, the mammalian target of rapamycin (mTOR) signaling pathway has recently been 


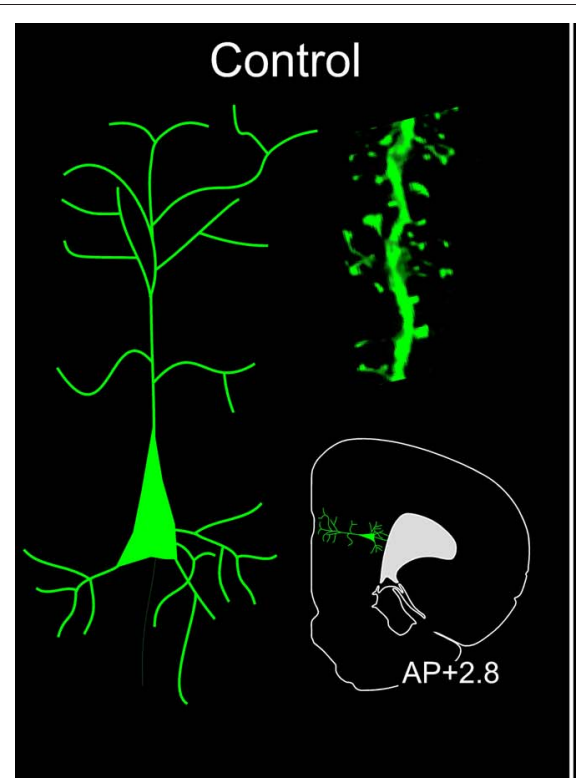

FIGURE 6 | Summary of effects of chronic stress on structural plasticity in mPFC pyramidal neurons. In these studies (Radley et al., 2004, 2006b, 2008a), high resolution analyses were performed in digitally reconstructed dendritic segments from fluorescent dye-injected pyramidal neurons in dorsal anterior cingulate $(\mathrm{ACd})$ and prelimbic $(\mathrm{PL})$ areas. An atlas plate (lower left) depicts the approximate region within $\mathrm{MPFC}$ that neurons were filled

implicated in synaptic deficits that result from excessive glutamatergic stimulation, such as that which ensues under chronic stress (Magarinos and McEwen, 1995b; Li et al., 2011). These studies highlight potentially important cellular mechanisms for investigating their role in the circuit alterations underlying neuroendocrine adjustments following chronic stress.

From the network perspective, large-scale decreases and destabilization of the excitatory synapse population in $\mathrm{mPFC}$ and HF could uncouple excitatory afferent input from excitatory outflow in PL and/or HF, resulting in their diminished influence over PVHprojecting GABAergic neurons in aBST. Concurrent increases in BLA neuronal dendritic branching and spine densities could also drive disinhibition of PVH-projecting GABAergic neurons, via increasing activation in the extrinsic GABAergic projections from $\mathrm{CeA}$. One challenge concerns whether changes throughout the entire network are necessary for HPA axis hyperactivity following chronic stress, or whether this phenotype is regulated by a distinct pathway or mechanism. As many of the stress-related changes in $\mathrm{HF}$ have been demonstrated more dorsally in CA3, and to some extent in DG and CA1 (e.g., Sousa et al., 2000; Snyder et al., 2011) it is unclear whether vSUB serves as a way station, or whether stress effects within vSUB proper (or ventral hippocampus) account for alterations in excitatory outflow to aBST. Another issue concerns the fact that little is known about how chronic stress impacts other cell groups implicated in the stress-inhibitory network, such as PVTp and lateral septum. The fact that GCs appear capable to exert widespread effects throughout the cortex, inclusive of sensorimotor regions (Liston and Gan, 2011), poses additional challenges in teasing apart neural circuits that underlie stress-related behavioral and physiological alterations.

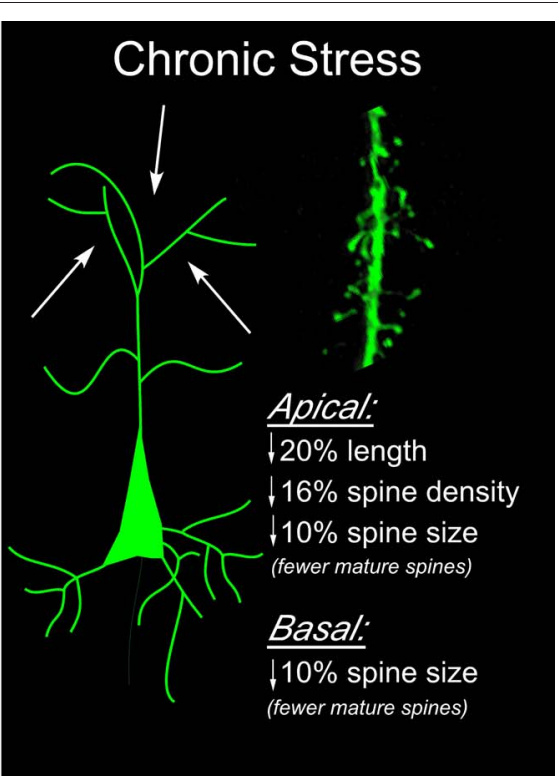

for morphologic analyses. Distance in millimeters relative to bregma is indicated. Arrows highlight the fact that dendritic atrophy and spine/excitatory synapse loss is most prominent on distal apical dendrites (right). Spine morphologic analyses reveal fewer spines with mature (stubby,

mushroom-shaped), and a greater number with immature (long and thin) phenotype.

\section{SUMMARY}

It has been previously established that the HPA axis response to emotional stress involves a network of limbic forebrain afferents that exert their effects on the PVH via multisynaptic and parallel pathways. Recent evidence lends support for at least two limbic cortical regions, $\mathrm{mPFC}$ and HF, that impart their inhibitory influences over the stress axis by converging on a discrete target, the aBST, that in turn inhibits the PVH and HPA activity. Importantly, GABAergic neurons in the aBST exhibit the capacity to integrate the inhibitory prefrontal and hippocampal influences that they impart on the stress axis. There are a number of hypotheses that derive from this model that should help to inform future work. One idea is that aBST serves as a neural hub for receiving and integrating stress-modulatory influences from other limbic forebrain regions (i.e., PVTp, septum, amygdala). Another implication is that this network, notably via GABAergic relays in aBST, may serve to integrate GC receptor-mediated negative feedback signals from some, if not all of, these limbic forebrain regions via a presynaptic endocannabinoid signaling mechanism. As this network is inhibitory, this may help to inform the search for HPA-activating networks; i.e., something akin to the medullary aminergic inputs to PVH that are known to drive HPA output in response to physiological stressors.

Chronic stress-induced neuroplasticity throughout the limbic cortex, or within key regions, may lead to an attrition of their excitatory influence on the PVH-projecting GABAergic cell population in aBST, producing HPA axis hyperactivity. A key feature of this hypothesis is that regressive changes are evident in regions that normally serve to inhibit HPA axis activation during emotionally stressful experiences, and hypertrophic 
changes (i.e., increased branching and synapse number) are evident in regions that contribute an excitatory influence on HPA output. Whereas considerable gains have been made in understanding the cellular mechanisms underlying dendritic spine dynamics, much of this work has not been applied to enhance our knowledge of how chronic stress leads to long-term changes in neuroendocrine function. Moreover, examination of why stress and GCs have bidirectional effects on excitatory synapse plasticity in BLA, relative to HF and $\mathrm{mPFC}$, may shed light on what are likely to be categorically distinct effects on the regulation of gene expression in these cell types that are imparted by GCs. Finally, susceptibility to stress-related psychiatric illnesses depends on a

\section{REFERENCES}

Akana, S. F., Chu, A., Soriano, L., and Dallman, M. F. (2001). Corticosterone exerts site-specific and state-dependent effects in prefrontal cortex and amygdala on regulation of adrenocorticotropic hormone, insulin and fat depots. J. Neuroendocrinol. 13, 625-637.

Allen, J. P., Allen, C. F., Greer, M. A., and Jacobs, J. J. (1971). Stressinduced Secretion of ACTH. Basel: Karger.

Antoni, F. A. (1986). Hypothalamic control of adrenocorticotropin secretion: advances since the discovery of 41-residue corticotropinreleasing factor. Endocr. Rev. 7, 351-378.

Arnsten, A. F. (2009). Stress signalling pathways that impair prefrontal cortex structure and function. Nat. Rev. Neurosci. 10, 410-422.

Bailey, C. H., and Kandel, E. R. (1993). Structural changes accompanying memory storage. Annu. Rev. Physiol. 55, 397-426.

Bhatnagar, S., and Dallman, M. (1998). Neuroanatomical basis for facilitation of hypothalamic-pituitaryadrenal responses to a novel stressor after chronic stress. Neuroscience 84, 1025-1039.

Bhatnagar, S., Vining, C., and Denski, K. (2004). Regulation of chronic stress-induced changes in hypothalamic-pituitary-adrenal activity by the basolateral amygdala. Ann. N.Y. Acad. Sci. 1032, 315-319.

Campeau, S., Falls, W. A., Cullinan, W. E., Helmreich, D. L., Davis, M., and Watson, S. J. (1997). Elicitation and reduction of fear: behavioural and neuroendocrine indices and brain induction of the immediateearly gene c-fos. Neuroscience 78, 1087-1104.

Canteras, N. S., and Swanson, L. W. (1992). Projections of the ventral subiculum to the amygdala, septum, and hypothalamus: a PHAL anterograde tract-tracing study in the rat. J. Comp. Neurol. 324, 180-194.
Carroll, Curtis, G. C., and Mendels, J. (1976). Neuroendocrine regulation in depression. I. Limbic systemadrenocortical dysfunction. Arch. Gen. Psychiatry 33, 1039-1044.

Choi, D. C., Furay, A. R., Evanson, N. K., Ostrander, M. M., Ulrich-Lai, Y. M., and Herman, J. P. (2007). Bed nucleus of the stria terminalis subregions differentially regulate hypothalamic-pituitary-adrenal axis activity: implications for the integration of limbic inputs. J. Neurosci. 27, 2025-2034.

Conrad, C. D. (2008). Chronic stressinduced hippocampal vulnerability: the glucocorticoid vulnerability hypothesis. Rev. Neurosci. 19, 395-411.

Conrad, C. D. (2010). A critical review of chronic stress effects on spatial learning and memory. Prog. Neuropsychopharmacol. Biol. Psychiatry 34, 742-755.

Cook, S. C., and Wellman, C. L. (2004). Chronic stress alters dendritic morphology in rat medial prefrontal cortex. J. Neurobiol. 60, 236-248.

Cullinan, W. E., Herman, J. P., Battaglia, D. F., Akil, H., and Watson, S. J. (1995). Pattern and time course of immediate early gene expression in rat brain following acute stress. Neuroscience 64, 477-505.

Cullinan, W. E., Herman, J. P., and Watson, S. J. (1993). Ventral subicular interaction with the hypothalamic paraventricular nucleus: evidence for a relay in the bed nucleus of the stria terminalis. J. Comp. Neurol. 332, 1-20.

Dallman, M. F., Akana, S. F., Scribner, K. A., Bradbury, M. J., Walker, C. D., Strack, A. M., and Cascio, C. S. (1992). Stress, feedback and facilitation in the hypothalamo-pituitaryadrenal axis. J. Neuroendocrinol. 4, 517-526.

Day, T. A. (2005). Defining stress as a prelude to mapping its neurocircuitry: no help from allostasis. Prog. Neuropsychopharmacol. Biol. Psychiatry 29, 1195-1200.

number of factors (e.g., genetics, early-life experiences, previous stress exposure) that may help to explain why some individuals go on to develop stress-related disorders while others do not. The extent to which structural plasticity in limbic cortical regions is predictive of adaptation or failure of stress/HPA control systems is of fundamental importance for informing the issue of how these more complex hereditary and environmental factors may tip the balance between stress resilience and pathology.

\section{ACKNOWLEDGMENTS}

This work was supported by National Institutes of Health Grant MH-095972.

Dayas, C. V., Buller, K. M., Crane, J. W., Xu, Y., and Day, T. A. (2001). Stressor categorization: acute physical and psychological stressors elicit distinctive recruitment patterns in the amygdala and in medullary noradrenergic cell groups. Eur. J. Neurosci. 14, 1143-1152.

Dias-Ferreira, E., Sousa, J. C., Melo, I., Morgado, P., Mesquita, A. R., Cerqueira, J. J., Costa, R. M., and Sousa, N. (2009). Chronic stress causes frontostriatal reorganization and affects decision-making. Science 325, 621-625.

Diorio, D., Viau, V., and Meaney, M. J. (1993). The role of the medial prefrontal cortex (cingulate gyrus) in the regulation of hypothalamicpituitary-adrenal responses to stress. J. Neurosci. 13, 3839-3847.

Dong, H. W., Petrovich, G. D., Watts, A. G., and Swanson, L. W. (2001). Basic organization of projections from the oval and fusiform nuclei of the bed nuclei of the stria terminalis in adult rat brain. J. Comp. Neurol. 436, 430-455.

Drevets, W. C., Price, J. L., Simpson, J. R. Jr., Todd, R. D., Reich, T., Vannier, M., and Raichle, M. E. (1997). Subgenual prefrontal cortex abnormalities in mood disorders. Nature 386, 824-827.

Duman, R. S., and Voleti, B. (2012). Signaling pathways underlying the pathophysiology and treatment of depression: novel mechanisms for rapid-acting agents. Trends Neurosci. 35, 47-56.

Dunn, J. D. (1987). Plasma corticosterone responses to electrical stimulation of the bed nucleus of the stria terminalis. Brain Res. 407, 327-331.

Feldman, S., and Conforti, N. (1980a). Adrenocortical responses in dexamethasone-treated rats with septal, preoptic and combined hypothalamic lesions. Horm. Res. 12, 289-295.

Feldman, S., and Conforti, N. (1980b). The role of the medial septal nucleus in mediating adrenocortical responses to somatosensory stimulation. J. Neurosci. Res. 5, 19-23.

Figueiredo, H. F., Bodie, B. L., Tauchi, M., Dolgas, C. M., and Herman, J. P. (2003a). Stress integration after acute and chronic predator stress: differential activation of central stress circuitry and sensitization of the hypothalamo-pituitaryadrenocortical axis. Endocrinology 144, 5249-5258.

Figueiredo, H. F., Bruestle, A., Bodie, B., Dolgas, C. M., and Herman, J. P. (2003b). The medial prefrontal cortex differentially regulates stressinduced c-fos expression in the forebrain depending on type of stressor. Eur. J. Neurosci. 18, 2357-2364.

Fortier, C. (1951). Dual control of adrenocorticotrophin release. Endocrinology 49, 782-788.

Hains, A. B., Vu, M. A., Maciejewski, P. K., van Dyck, C. H., Gottron, M., and Arnsten, A. F. (2009). Inhibition of protein kinase $\mathrm{C}$ signaling protects prefrontal cortex dendritic spines and cognition from the effects of chronic stress. Proc. Natl. Acad. Sci. U.S.A. 106, 17957-17962.

Hajszan, T., Dow, A., Warner-Schmidt, J. L., Szigeti-Buck, K., Sallam, N. L., Parducz, A., Leranth, C., and Duman, R. S. (2009). Remodeling of hippocampal spine synapses in the rat learned helplessness model of depression. Biol. Psychiatry 65, 392-400.

Heidbreder, C. A., and Groenewegen, H. J. (2003). The medial prefrontal cortex in the rat: evidence for a dorso-ventral distinction based upon functional and anatomical characteristics. Neurosci. Biobehav. Rev. 27, 555-579.

Herman, J. P., and Cullinan, W. E. (1997). Neurocircuitry of stress: central control of the hypothalamopituitary-adrenocortical axis. Trends Neurosci. 20, 78-84.

Herman, J. P., Cullinan, W. E., Morano, M. I., Akil, H., and Watson, 
S. J. (1995). Contribution of the ventral subiculum to inhibitory regulation of the hypothalamopituitary-adrenocortical axis. J. Neuroendocrinol. 7, 475-482.

Herman, J. P., Figueiredo, H., Mueller, N. K., Ulrich-Lai, Y., Ostrander, M. M., Choi, D. C., and Cullinan, W. E. (2003). Central mechanisms of stress integration: hierarchical circuitry controlling hypothalamo-pituitaryadrenocortical responsiveness. Front. Neuroendocrinol. 24, 151-180.

Herman, J. P., and Mueller, N. K. (2006). Role of the ventral subiculum in stress integration. Behav. Brain Res. 174, 215-224.

Hill, M. N., Mclaughlin, R. J., Pan, B., Fitzgerald, M. L., Roberts, C. J., Lee, T. T., Karatsoreos, I. N., Mackie, K., Viau, V., Pickel, V. M., McEwen, B. S., Liu, Q. S., Gorzalka, B. B., and Hillard, C. J. (2011). Recruitment of prefrontal cortical endocannabinoid signaling by glucocorticoids contributes to termination of the stress response. J. Neurosci. 31, 10506-10515.

Holmes, A., and Wellman, C. L. (2009). Stress-induced prefrontal reorganization and executive dysfunction in rodents. Neurosci. Biobehav. Rev. 33, 773-783.

Jacobson, L., and Sapolsky, R. (1991). The role of the hippocampus in feedback regulation of the hypothalamic-pituitaryadrenocortical axis. Endocr. Rev. 12, 118-134.

Jaferi, A., and Bhatnagar, S. (2006). Corticosterone can act at the posterior paraventricular thalamus to inhibit hypothalamic-pituitaryadrenal activity in animals that habituate to repeated stress. Endocrinology 147, 4917-4930.

Kasai, H., Matsuzaki, M., Noguchi, J., Yasumatsu, N., and Nakahara, H. (2003). Structure-stability-function relationships of dendritic spines. Trends Neurosci. 26, 360-368.

Kessler, R. C. (1997). The effects of stressful life events on depression. Annu. Rev. Psychol. 48, 191-214.

Kuipers, S. D., Trentani, A., Den Boer, J. A., and Ter Horst, G. J. (2003). Molecular correlates of impaired prefrontal plasticity in response to chronic stress. J. Neurochem. 85, 1312-1323.

LeDoux, J. E. (2000). Emotion circuits in the brain. Annu. Rev. Neurosci. 23, 155-184.

Li, H. Y., and Sawchenko, P. E. (1998). Hypothalamic effector neurons and extended circuitries activated in "neurogenic" stress: a comparison of footshock effects exerted acutely, chronically, and in animals with controlled glucocorticoid levels. J. Comp. Neurol. 393, 244-266.

Li, N., Lee, B., Liu, R. J., Banasr, M., Dwyer, J. M., Iwata, M., Li, X. Y., Aghajanian, G., and Duman, R. S. (2011). mTOR-dependent synapse formation underlies the rapid antidepressant effects of NMDA antagonists. Science 329, 959-964.

Liston, C., and Gan, W. B. (2011). Glucocorticoids are critical regulators of dendritic spine development and plasticity in vivo. Proc. Natl. Acad. Sci. U.S.A. 108, 16074-16079.

Liston, C., Miller, M. M., Goldwater, D. S., Radley, J. J., Rocher, A. B., Hof, P. R., Morrison, J. H., and Mcewen, B. S. (2006). Stress-induced alterations in prefrontal cortical dendritic morphology predict selective impairments in perceptual attentional set-shifting. J. Neurosci. 26, 7870-7874.

Liu, R. J., and Aghajanian, G. K. (2008). Stress blunts serotoninand hypocretin-evoked EPSCs in prefrontal cortex: role of corticosterone-mediated apical dendritic atrophy. Proc. Natl. Acad. Sci. U.S.A. 105, 359-364.

Liu, R. J., Lee, F. S., Li, X. Y., Bambico, F., Duman, R. S., and Aghajanian, G. K. (2012). Brain-derived neurotrophic factor Val66Met allele impairs basal and ketaminestimulated synaptogenesis in prefrontal cortex. Biol. Psychiatry.

Liu, N., Liu, R. J., Dwyer, J. M., Banasr, M., Lee, B., Son, H., Li, X. Y., Aghajanian, G., and Duman, R. S. (2008). Glutamate N-methyl-Daspartate receptor antagonists rapidly reverse behavioral and synaptic deficits caused by chronic stress exposure. Biol. Psychiatry 69, 754-761.

Luine, V., Villegas, M., Martinez, C., and McEwen, B. S. (1994). Repeated stress causes reversible impairments of spatial memory performance. Brain Res. 639, 167-170.

Magarinos, A. M., and McEwen, B. S. (1995a). Stress-induced atrophy of apical dendrites of hippocampal CA3c neurons: comparison of stressors. Neuroscience 69, 83-88.

Magarinos, A. M., and McEwen, B. S. (1995b). Stress-induced atrophy of apical dendrites of hippocampal CA3c neurons: involvement of glucocorticoid secretion and excitatory amino acid receptors. Neuroscience 69, 89-98.

Magarinos, A. M., Verdugo, J. M., and McEwen, B. S. (1997). Chronic stress alters synaptic terminal structure in hippocampus.
Proc. Natl. Acad. Sci. U.S.A. 94, 14002-14008.

Malthe-Sorenssen, D., Odden, E., and Walaas, I. (1980). Selective destruction by kainic acid of neurons innervated by putative glutamergic afferents in septum and nucleus of the diagonal band. Brain Res. 182, 461-465.

McIntyre, C. K., Power, A. E., Roozendaal, B., and McGaugh, J. L. (2003). Role of the basolateral amygdala in memory consolidation. Ann. N.Y. Acad. Sci. 985, 273-293.

Michelsen, K. A., van den Hove, D. L., Schmitz, C., Segers, O., Prickaerts, J., and Steinbusch, H. W. (2007). Prenatal stress and subsequent exposure to chronic mild stress influence dendritic spine density and morphology in the rat medial prefrontal cortex. BMC Neurosci. 8, 107.

Mitra, R., Jadhav, S., Mcewen, B. S., Vyas, A., and Chattarji, S. (2005). Stress duration modulates the spatiotemporal patterns of spine formation in the basolateral amygdala. Proc. Natl. Acad. Sci. U.S.A. 102, 9371-9376.

Morgan, M. A., and LeDoux, J. E. (1995). Differential contribution of dorsal and ventral medial prefrontal cortex to the acquisition and extinction of conditioned fear in rats Behav. Neurosci. 109, 681-688.

Nibuya, M., Morinobu, S., and Duman, R. S. (1995). Regulation of BDNF and trkB mRNA in rat brain by chronic electroconvulsive seizure and antidepressant drug treatments. J. Neurosci. 15, 7539-7547.

Ottenweller, J. E., Natelson, B. H., Pitman, D. L., and Drastal, S. D. (1989). Adrenocortical and behavioral responses to repeated stressors: toward an animal model of chronic stress and stress-related mental illness. Biol. Psychiatry 26, 829-841.

Ottersen, O. P., Hjelle, O. P., Osen, K. K., and Laake, J. H. (1995). Amino Acid Transmitters. San Diego, CA: Academic.

Pitkanen, A., Savander, V., and LeDoux, J. E. (1997). Organization of intraamygdaloid circuitries in the rat: an emerging framework for understanding functions of the amygdala. Trends Neurosci. 20, 517-523.

Prewitt, C. M., and Herman, J. P. (1997). Hypothalamo-PituitaryAdrenocortical Regulation Following Lesions of the Central Nucleus of the Amygdala. Stress 1, 263-280.

Radley, J. J., Arias, C. M., and Sawchenko, P. E. (2006a). Regional differentiation of the medial prefrontal cortex in regulating adaptive responses to acute emotional stress. J. Neurosci. 26, 12967-12976.

Radley, J. J., Gosselink, K. L., and Sawchenko, P. E. (2009). A discrete GABAergic relay mediates medial prefrontal cortical inhibition of the neuroendocrine stress response. J. Neurosci. 29, 7330-7340.

Radley, J. J., Rocher, A. B., Miller, M., Janssen, W. G., Liston, C., Hof, P. R., McEwen, B. S., and Morrison, J. H. (2006b). Repeated stress induces dendritic spine loss in the rat medial prefrontal cortex. Cereb. Cortex 16, 313-320.

Radley, J. J., Rocher, A. B., Rodriguez, A., Ehlenberger, D. B., Dammann, M., McEwen, B. S., Morrison, J. H., Wearne, S. L., and Hof, P. R. (2008a). Repeated stress alters dendritic spine morphology in the rat medial prefrontal cortex. J. Comp. Neurol. 507, 1141-1150.

Radley, J. J., and Sawchenko, P. E. (2011). A common substrate for prefrontal and hippocampal inhibition of the neuroendocrine stress response. J. Neurosci. 31, 9683-9695.

Radley, J. J., Sisti, H. M., Hao, J., Rocher, A. B., McCall, T., Hof, P. R., McEwen, B. S., and Morrison, J. H. (2004). Chronic behavioral stress induces apical dendritic reorganization in pyramidal neurons of the medial prefrontal cortex. Neuroscience 125, 1-6.

Radley, J. J., Williams, B., and Sawchenko, P. E. (2008b). Noradrenergic innervation of the dorsal medial prefrontal cortex modulates hypothalamopituitary-adrenal responses to acute emotional stress. J. Neurosci. 28, 5806-5816.

Ritter, S., Watts, A. G., Dinh, T. T., Sanchez-Watts, G., and Pedrow, C. (2003). Immunotoxin lesion of hypothalamically projecting norepinephrine and epinephrine neurons differentially affects circadian and stressorstimulated corticosterone secretion. Endocrinology 144, 1357-1367.

Roland, B. L., and Sawchenko, P. E. (1993). Local origins of some GABAergic projections to the paraventricular and supraoptic nuclei of the hypothalamus in the rat. $J$. Comp. Neurol. 332, 123-143.

Sandi, C., Davies, H. A., Cordero, M. I., Rodriguez, J. J., Popov, V. I., and Stewart, M. G. (2003). Rapid reversal of stress induced loss of synapses in CA3 of rat hippocampus following water maze training. Eur. J. Neurosci. 17, 2447-2456.

Sapolsky, R. M., Krey, L. C., and McEwen, B. S. (1986). The 
neuroendocrinology of stress and aging: the glucocorticoid cascade hypothesis. Endocr. Rev. 7, 284-301.

Sawchenko, P. E., Li, H. Y., and Ericsson, A. (2000). Circuits and mechanisms governing hypothalamic responses to stress: a tale of two paradigms. Prog. Brain Res. 122, 61-78.

Schiltz, J. C., and Sawchenko, P. E. (2007). Specificity and generality of the involvement of catecholaminergic afferents in hypothalamic responses to immune insults. J. Comp. Neurol. 502, 455-467.

Selye, H. (1980). Stress in Health and Disease. Boston, MA: Butterworths.

Sesack, S. R., Deutch, A. Y., Roth, R. H., and Bunney, B. S. (1989). Topographical organization of the efferent projections of the medial prefrontal cortex in the rat: an anterograde tract-tracing study with Phaseolus vulgaris leucoagglutinin. J. Comp. Neurol. 290, 213-242.

Sheline, Y. I., Gado, M. H., and Kraemer, H. C. (2003). Untreated depression and hippocampal volume loss. Am. J. Psychiatry 160, 1516-1518.

Sheline, Y. I., Wang, P. W., Gado, M. H., Csernansky, J. G., and Vannier, M. W. (1996). Hippocampal atrophy in recurrent major depression. Proc. Natl. Acad. Sci. U.S.A. 93, 3908-3913.

Shin, J. W., Geerling, J. C., and Loewy, A. D. (2008). Inputs to the ventrolateral bed nucleus of the stria terminalis. J. Comp. Neurol. 511, 628-657.

Snyder, J. S., Soumier, A., Brewer, M., Pickel, J., Cameron, H. A. (2011). Adult hippocampal neurogenesis buffers stress responses and depressive behaviour. Nature 476, 458-461.

Shors, T. J., Weiss, C., and Thompson, R. F. (1992). Stress-induced facilitation of classical conditioning. Science 257, 537-539.

Sorra, K. E., and Harris, K. M. (2000). Overview on the structure, composition, function, development, and plasticity of hippocampal dendritic spines. Hippocampus 10, 501-511.

Sousa, N., Lukoyanov, N. V., Madeira, M. D., Almeida, O. F., and Paula-Barbosa, M. M. (2000). Reorganization of the morphology of hippocampal neurites and synapses after stress-induced damage correlates with behavioral improvement. Neuroscience 97, 253-266.

Spencer, S. J., Buller, K. M., and Day, T. A. (2005). Medial prefrontal cortex control of the paraventricular hypothalamic nucleus response to psychological stress: possible role of the bed nucleus of the stria terminalis. J. Comp. Neurol. 481, 363-376.

Stewart, M. G., Davies, H. A., Sandi, C., Kraev, I. V., Rogachevsky, V. V., Peddie, C. J., Rodriguez, J. J., Cordero, M. I., Donohue, H. S., Gabbott, P. L., and Popov, V. I. (2005). Stress suppresses and learning induces plasticity in CA3 of rat hippocampus: a three-dimensional ultrastructural study of thorny excrescences and their postsynaptic densities. Neuroscience 131, 43-54.

Sullivan, G. M., Apergis, J., Bush, D. E., Johnson, L. R., Hou, M., and LeDoux, J. E. (2004). Lesions in the bed nucleus of the stria terminalis disrupt corticosterone and freezing responses elicited by a contextual but not by a specific cue-conditioned fear stimulus. Neuroscience 128, 7-14.

Sullivan, R. M., and Gratton, A. (1999). Lateralized effects of medial prefrontal cortex lesions on neuroendocrine and autonomic stress responses in rats. J. Neurosci. 19, 2834-2840.
Sun, N., and Cassell, M. D. (1993). Intrinsic GABAergic neurons in the rat central extended amygdala. J. Comp. Neurol. 330, 381-404.

Swanson, L. W., and Cowan, W. M. (1977). An autoradiographic study of the organization of the efferent connections of the hippocampal formation in the rat. J. Comp. Neurol. 172, 49-84.

Tsubouchi, K., Tsumori, T., Yokota, S., Okunishi, H., and Yasui, Y. (2007). A disynaptic pathway from the central amygdaloid nucleus to the paraventricular hypothalamic nucleus via the parastrial nucleus in the rat. Neurosci. Res. 59, 390-398.

van de Kar, L. D., and Blair, M. L. (1999). Forebrain pathways mediating stress-induced hormone secretion. Front. Neuroendocrinol. 20, 1-48.

Vertes, R. P. (2004). Differential projections of the infralimbic and prelimbic cortex in the rat. Synapse 51, 32-58.

Vyas, A., Jadhav, S., and Chattarji, S. (2006). Prolonged behavioral stress enhances synaptic connectivity in the basolateral amygdala. Neuroscience 143, 387-393.

Vyas, A., Mitra, R., Shankaranarayana Rao, B. S., and Chattarji, S. (2002). Chronic stress induces contrasting patterns of dendritic remodeling in hippocampal and amygdaloid neurons. J. Neurosci. 22, 6810-6818.

Walaas, I., and Fonnum, F. (1980). Biochemical evidence for glutamate as a transmitter in hippocampal efferents to the basal forebrain and hypothalamus in the rat brain. Neuroscience 5, 1691-1698.

Watanabe, Y., Gould, E., and McEwen, B. S. (1992). Stress induces atrophy of apical dendrites of hippocampal CA3 pyramidal neurons. Brain Res. 588, 341-345.

Weinberg, M. S., Grissom, N., Paul, E., Bhatnagar, S., Maier, S. F., and
Spencer, R. L. (2010). Inescapable but not escapable stress leads to increased struggling behavior and basolateral amygdala c-fos gene expression in response to subsequent novel stress challenge. Neuroscience 170, 138-148.

Wilbrecht, L., Holtmaat, A., Wright, N., Fox, K., and Svoboda, K. (2010). Structural plasticity underlies experience-dependent functional plasticity of cortical circuits J. Neurosci. 30, 4927-4932.

Willner, P. (1997). Validity, reliability and utility of the chronic mild stress model of depression: a 10-year review and evaluation. Psychopharmacology (Berl.) 134, 319-329.

Yehuda, R. (2002). Post-traumatic stress disorder. N. Engl. J. Med. 346, 108-114.

Conflict of Interest Statement: The author declares that the research was conducted in the absence of any commercial or financial relationships that could be construed as a potential conflict of interest.

Received: 05 June 2011; paper pending published: 02 September 2011; accepted: 10 February 2012; published online: 29 March 2012.

Citation: Radley JJ (2012) Toward a limbic cortical inhibitory network: implications for hypothalamic-pituitary-adrenal responses following chronic stress. Front. Behav. Neurosci. 6:7. doi: 10.3389/fnbeh. 2012.00007

Copyright (c) 2012 Radley. This is an open-access article distributed under the terms of the Creative Commons Attribution Non Commercial License, which permits non-commercial use, distribution, and reproduction in other forums, provided the original authors and source are credited. 